\title{
PARA LA RECONSTRUCCIÓN DEL SENTIDO DE LO POLÍTICO*
}

\section{Julio De Zan ${ }^{* *}$}

Resumen: El artículo parte de la crítica de $\mathrm{H}$. Arendt a la posición de la filosofía frente a la política desde Platón hasta Marx y Heidegger. Esta fuerte crítica de la tradición filosófica, especialmente de su relación con la política, no es simplemente una crítica de la filosofía política, sino de la filosofía sin más, pero centrada en esta relación, o falta de relación con la política, y en la contribución de la filosofía al oscurecimiento y el olvido del sentido de lo político en la historia moderna y contemporánea. Se trata de un ejercicio de crítica interna de la filosofía y de la política como paso para el redescubrimiento del sentido originario de la polis en la Grecia antigua, y para la reconstrucción actual del sentido de lo político.

Palabras clave: política, filosofía, polis, Estado, ciudadanía.

Abstract: The starting point of this paper is $\mathrm{H}$. Arendt criticism of philosophical tradition in front of politics from Plato to Marx and Heidegger. This strong criticism of philosophical tradition is not simply a criticism of political philosophy, but of philosophy itself centered in its relationship, or lack of relationship, to politics, and in the contribution of philosophy to the darkening and oblivion of the meaning of politics in modern and contemporary history. It is an exercise of internal criticism of philosophy and politics as a step to the rediscovery of the original meaning of the polis in ancient Greece, and for the current reconstruction of the meaning of politics.

Key words: politics, philosophy, polis, State, citizenship.

“Por lo general el término 'político' es equiparado de alguna manera con 'estatal', o por lo menos es referido al Estado (...) Pero el Estado, conforme al uso corriente del lenguaje jurídico,

* La primera parte del texto aquí presentado condensa y reformula parte de la exposición del Capítulo 3 (pp. 75-107) del libro del autor: J. De Zan La vieja y la nueva politica. Libertad, poder y discurso, UNSAM Edita, Buenos Aires, 2013.

** Investigador Principal del CONICET. Profesor Titular de la Universidad Nacional de San Martín. Dirección electrónica: jdezan@fibertel.com.ar 
es el estatus político de un pueblo organizado dentro de unas fronteras territoriales. El Estado aparece entonces como algo político, y lo político, a su vez, como algo estatal. Estamos evidentemente en un círculo vicioso" (C. Schmitt, Der Begriff des Politischen, 1932).

" $[\mathrm{La}$ academia] se instituyó precisamente conforme al sentido de ese espacio greco-ateniense, específicamente político -en el que el hablar los unos con los otros fue su auténtica actividad. Con ello surgió, junto al territorio libre de lo político, un espacio nuevo de la libertad que ha llegado hasta nuestros días como la libertad de las universidades, la libertad académica de cátedra (...) También esta libertad es de naturaleza completamente política. El espacio libre de la academia debía ser un sustituto plenamente válido de la plaza del mercado, el agora, que era el espacio libre central de la polis (...) Es en este contexto [de la academia platónica] que se dice por primera vez que la política deriva de una necesidad, que lo político en su conjunto es un medio necesario para un fin más elevado, el cual se sitúa más allá de lo político mismo" (H. Arendt, Was ist Politik?, 1956/1959).

El trabajo de la reconstrucción racional del sentido y la validez comienza con el cuestionamiento de los lugares comunes, o de las aparentes obviedades naturalizadas por los usos corrientes del lenguaje que nos impiden pensar y plantearnos la cuestión del sentido.

Las transformaciones políticas de fin de siglo y el debilitamiento de la institucionalidad estatal, han abierto en la filosofía política más reciente los espacios para una "deconstrucción" del sistema de poder instituido en el Estado, que hace posible redescubrir y hacer jugar entre las grietas de la estructura jurídica formal de este sistema el sentido originario más profundo de lo político y de la democracia. Ya Carl Schmitt comenzaba el libro citado en el acápite con una sentencia que ha hecho 
época: "el concepto del Estado presupone el concepto de lo político"2. Aquí me apoyaré más bien en Hannah Arendt, quien también piensa que la ciudadanía y el sentido de lo político se definen independientemente de la constitución del Estado, de tal manera que es posible y necesario pensar y comprender lo político como anterior a toda institucionalidad jurídica y estatal. Puede decirse por cierto que la institucionalidad es necesaria, que lo político no puede realizarse, o estabilizarse, sin instituciones. Esto es verdad, pero también me parece que la superestructura institucional oscurece el sentido de lo político, y tiende fatalmente a reemplazarlo. Y aunque no se esté de acuerdo con esto último, habrá que admitir por lo menos que, de acuerdo con la lógica de las cosas mismas, hay que entender las instituciones a partir de aquello anterior que se institucionaliza y no a la inversa. La diferencia y la ambigüedad de la relación de lo existencial y lo institucional no es un problema propio, particular de lo político, sino de toda experiencia de este tipo, o de toda idea práctica que baja al terreno de la institucionalidad. Me gustaría decir que, entre la libertad política y la institución estatal, hay una relación semejante a la del amor y la institución matrimonial, o de la religiosidad y la institución eclesiástica.

Lo político implica solamente la existencia de una pluralidad de hombres que interactúan en libertad. Es una experiencia existencial de reconocimiento mutuo y de acción en común. Y de hecho históricamente el léxico de lo político se formó y era usado con precisión en Grecia antes de la formación del Estado. El desarrollo posterior de la estatalidad en la historia real, y la evolución semántica del lenguaje de lo político, pueden relatarse en cambio, según veremos enseguida, como la historia del oscurecimiento y del olvido del sentido de lo político. La historia de este olvido ha tenido su consumación en la filosofía del siglo XX con el discurso rectoral de Heidegger en 1933.

Según la manera más corriente de comenzar a hablar de la política, ésta ha existido siempre y en todo lugar como algo que es

2 C. Schmitt, Der Begriff des Staates setzt den Begriff des Politischen voraus, Berlin, Dunkel \& Humboldt Verlag, 1979, p. 20. 
necesario para la vida, o la subsistencia, por el hecho de que el individuo humano no es autosuficiente para proveer por sí solo a todas las necesidades de su propia naturaleza. Pero esta suposición delata ya un oscurecimiento inicial del sentido que buscamos; no permite diferenciar lo político de lo económico-social, o de las formas de vida gregaria que encontramos también en el mundo animal.

Otra manera de abordar el tema es la que define lo político como un sistema de dominación. Ya Aristóteles contraponía, sin embargo, el dominio despótico y el gobierno político. En el primero no existe la libertad, sino el sometimiento y la desigualdad entre los que mandan y los que obedecen, o entre el señor y los siervos. La dominación amo-esclavo es por cierto muy primitiva, pero este tipo de relación no es política. La política es en cambio el régimen de la igualdad de los ciudadanos que se gobiernan a sí mismos y constituyen el sujeto social de una acción en común. Es claro que la política en este preciso sentido de una polis formada por hombres libres e iguales, donde todos mandan y todos obedecen (Aristóteles), no es algo que haya existido siempre y en todo lugar, sino que es, como la filosofía, una creación histórica de la época clásica de la cultura griega. Si bien nacen juntas, política y filosofía son por cierto cosas bien diferentes que mantienen relaciones generalmente conflictivas.

Por un lado, la filosofía tal como se entiende en la tradición occidental, implica la existencia de un espacio público de la libertad, como la polis, en el cual cada uno puede decir lo que piensa, confrontarlo con las opiniones y argumentos de los demás, y ejercer su capacidad de juicio autónomo, discutiendo críticamente las pretensiones de validez de las creencias y las prácticas comunes que sean inaceptables o reprochables. Pero en la medida en que la filosofía, desde Platón, se funda precisamente en la diferencia ontológica entre el mundo visible, de lo que aparece, y el mundo verdadero, que es invisible, el sentido de lo político y el valor del espacio público quedan oscurecidos o radicalmente cuestionados.

La verdad, el sentido de las cosas, del bien y de la justicia, se revelan en la meditación solitaria, en el silencio de la contemplación, en el diálogo interior del alma consigo misma, como decía Platón o, en todo caso, en un recinto selecto de los pocos como la academia. La filosofía 
parece haber olvidado, ya desde la antigüedad, sus orígenes dialógicos y su lugar en el ágora. Para el racionalismo moderno el uso público del lenguaje, la conversación y el discurso, no tienen que ver con la búsqueda de la verdad o con la producción intersubjetiva del saber, sino que cumplen una función instrumental, retórica o pedagógica, para trasmitir un conocimiento, o una decisión que se ha alcanzado por otra vía no discursiva, o no pública. Platón fue el primero en elaborar una filosofía política, pero en la concepción platónica de I a república la validez de las leyes no surge de la política misma, de la libre conversación de los ciudadanos en el espacio público, sino de la filosofía; las leyes deben corresponder a las ideas, a las que sólo el filósofo tiene acceso privilegiado ${ }^{3}$.

"La desjerarquización de la política a partir de la filosofía, tal como la vemos desde Platón y Aristóteles, depende completamente de la diferenciación de los pocos frente a los muchos, que ha tenido un efecto extraordinario, duradero hasta nuestros días, sobre todas las respuestas teóricas a la pregunta por el sentido de la política"4. Por otro lado, la forma que ha cobrado lo "político" en las instituciones del Estado moderno es heredera y continuadora del modelo medieval (en que los reyes deliberaban a puertas cerradas con los cortesanos y negociaban en secreto con los señores feudales), más que del sentido originario de lo político en la polis griega y en la primitiva república romana.

H. Arendt ha esbozado una fuerte autocrítica de la teoría política, desde Platón hasta Marx, y ha mostrado el papel que ha jugado la filosofía en esta historia del olvido del sentido de lo político. El discurso de la filosofía sobre "el hombre como animal político" se sitúa en un plano de abstracción que encubre en cierto modo la pluralidad y las diferencias de los hombres y de las mujeres, y hace imposible por lo tanto la aparición del problema mismo de la política.

${ }^{3}$ H. Arendt, Was ist Politik? Manuscrito inédito de 1956/1959. Trad. española: ¿Qué es la politica, Barcelona, Paidós, 1997, p. 80.

${ }^{4}$ Ibid., p. 84. 
La política se basa en el hecho de la existencia de la pluralidad de los hombres (...) ahora bien, en la medida en que la teología y la filosofía se ocupan siempre de el hombre en general, todos sus enunciados serían correctos incluso si sólo hubiera un hombre, o dos hombres, o únicamente hombres idénticos, por eso ellas no han podido encontrar ninguna respuesta filosófica y políticamente significativa a la pregunta ¿qué es la política? (...) La política trata del estar juntos, unos con otros, de los que son diferentes (...) el hombre es a-político. La política nace en el espacio entre-los-hombres"5.

Lo político no es nada ideal en el sentido platónico, y tampoco es un fenómeno de la naturaleza, sino el acontecer de muchas bistorias diferentes, pero entrelazadas; ${ }^{6}$ no es una cosa de las que existen por naturaleza (Aristóteles), ni de las que son fabricadas por el hombre (Hobbes), sino que pertenece al orden del acontecer, como la relación de amistad (o de enemistad) entre los hombres.

Si bien es cierto que la filosofía no se ha ocupado solamente de el hombre en abstracto, y la teoría política ha pensado también lo político en su devenir concreto y ha hablado del hombre como ser-con otros, Arendt considera que en estos tratamientos ha predominado la tendencia a la explicación de la existencia política a partir de totalidades abstractas e impersonales como "la historia", "el pueblo", "las clases sociales", "el Estado", o a partir de una ontología general en la que la singularidad humana queda de nuevo remitida a un destino del ser o a otras formas de la necesidad que no cuentan con la libertad.

I a ciudadanía en su realidad, no como un mero derecho, sino como implicación concreta del estado de derecho, es la propia existencia politica. Y el ejercicio de la ciudadanía consiste ante todo en la presencia de los ciudadanos en el espacio público, o en el aparecer y el hacerse visible a la luz pública mediante el uso de la palabra y mediante la facultad del juicio (Urteilkraft) y la capacidad de decisión en los asuntos comunes. La esencia

${ }^{5}$ Ibid., pp. 45-46.

${ }^{6}$ Cfr. J. De Zan, "Filosofía y política en Hannah Arendt", en Cuadernos del Sur, Revista de la Universidad Nacional del Sur, Bahía Blanca, 2003, pp. 11-36. 
de lo político es la visibilidad, en un sentido anti-platónico. La existencia política del ciudadano, su presencia en el espacio público, es el principio constituyente de lo político. El discurso público y el actuar juntos de los ciudadanos es lo que produce performativamente el "espacio público", o la "luz pública", que son los presupuestos constitutivos de lo político.

Lo público no puede entenderse por tanto como la propiedad de ninguna institución u organización formal y no debería confundirse con "lo estatal". Así como, según hemos visto, "el Estado presupone la existencia de lo político", tenemos que decir que presupone también la existencia de lo público: la res pública, la cosa pública. El concepto romano de la república mantiene vivo el sentido de lo político de la polis ateniense. En rigor, ambas cosas son lo mismo. El espacio público se comprende entonces independientemente del Estado, a partir de la presencia de ciudadanos libres, como el espacio comunicacional entre los interlocutores de un discurso y de una interacción comunicativa no meramente privada, ni excluyente. Lo público es esencialmente intersubjetivo, dinámico, $a^{a b i e r t o}{ }^{7}$. Es la interacción comunicativa horizontal entre los ciudadanos la que produce el espacio público y lo mantiene abierto.

La concepción hobbesiana del Estado moderno se construye en cambio mediante una lógica completamente diferente, que reemplaza esta horizontalidad de la relación constitutiva de lo político por una concepción vertical de la relación política como dominación, o como relación de mando y obediencia. La condición necesaria para construir la relación de poder como dominación y establecer la soberanía del Estado, definitoria de lo político, es que el pueblo se mantenga disgregado, sin vínculos políticos horizontales entre los individuos, y que la única relación política sea la relación vertical de mando y el temor que asegura la obediencia de cada uno de los súbditos al soberano. Puesto que la relación entre los hombres en el estado de naturaleza es para Hobbes en sí misma y fatalmente conflictiva, la estrategia del autor del Leviatán para eliminar la guerra de todos contra todos es la eliminación misma de esta relación. "Él [Hobbes] tiene cuidado de edificar el nuevo Estado de tal manera que

${ }^{7}$ Cfr.: J. Habermas, Facticidad y validez (1992), Madrid, Trotta, 1998, pp. 440-441. 
excluya toda posibilidad de conflicto recíproco entre los hombres"8. La manera radical de evitar los conflictos en la asociación "es la completa disociación". Así lo entiende también Schmitt en sus escritos sobre Hobbes, dice Esposito, cuando observa que el pacto está concebido de manera totalmente individualista: disuelve todo vínculo comunitario. $\mathrm{Y}$ así debe entenderse la prohibición -que Hobbes considera indeclinable para el funcionamiento de su modelo- de cualquier asociación autónoma dentro del Estado; porque no solamente amenazaría su poder soberano, sino que constituiría una negación de la propia lógica del modelo. La soberanía política coincide con la disociación, o la atomización de la sociedad reducida a una mera multiplicidad de individuos. La unidad política se anuda y pende enteramente de la única atadura directa de cada uno de los súbditos al poder del soberano. "El cuerpo político" construido por el contrato social, "no es solamente diferente, sino lo opuesto a la comunidad" . Súbditos del soberano son precisamente aquellos que no tienen políticamente nada en común, salvo su vínculo con el mismo soberano.

Para Max Weber lo político existe como una determinada forma de asociación que se diferencia de todo otro tipo de asociaciones porque sus miembros están sometidos a relaciones de dominación (Herrschaft). De manera más específica: una asociación de dominación debe llamarse política solamente cuando, y en la medida en que, la dominación disponga de los medios necesarios para garantizar la obediencia de sus miembros a los ordenamientos establecidos ${ }^{10}$. La asociación política no se define como tal por sus fines, sino por los medios físicos de coacción de los que solamente ella puede disponer para imponer obediencia, es decir, por el monopolio de la fuerza de las armas. En estas formulaciones de M. Weber se reitera el círculo vicioso de la definición de lo político y del Estado que su discípulo C. Schmitt ha denunciado. No obstante el fuerte lenguaje de la dominación y del mando respaldado en la fuerza, está claro también para Weber que la dominación política no es un régimen de mera fuerza,

${ }^{8}$ R. Espósito, Communitas, Buenos Aires, Amorrortu, 2003, p. 65.

${ }^{9}$ Ibid., p. 66.

${ }^{10}$ Sobre M. Weber, cfr. J. De Zan, La vieja y la nueva politica, ed. cit., pp. 123-133. 
sino que necesita apoyarse en una voluntad de obediencia, o en el interés de los que obedecen, y su famosa tipología de las formas de legitimación tiene por objeto explicar precisamente las causas o los motivos de esa obediencia que está en el origen y fundamento del poder político, y que recuerda el discurso de Étienne de la Boétie (1530-1563) sobre la "servidumbre voluntaria"11.

El sentido clásico de lo público y de lo político como liberación de toda forma de dominación o servidumbre había quedado oscurecido ya desde la época antigua, con la transformación de las primitivas repúblicas de Grecia y Roma en regímenes imperiales de dominación despótica sobre vastos territorios de diferentes naciones invadidas por los ejércitos de estos imperios. El relato de la historia política sea ha centrado casi siempre en este tipo de episodios de conquista militar $y$ en las luchas revolucionarias contra estas y otras formas de dominación de los pueblos. Lo político está en juego naturalmente en el trasfondo de estas historias, pero su sentido permanece en cierto modo confuso e indeterminado.

En el régimen feudal de la Edad Media no existieron ciudadanos autónomos, sino vasallos, súbditos del príncipe. Finalmente, con el individuo privado de la moderna sociedad burguesa, se profundiza el oscurecimiento y el olvido del sentido de las palabras claves del léxico de lo político. La privatización del ciudadano significa la desaparición del espacio público y, por lo tanto, de la diferencia misma entre lo público y lo privado. Solamente en los momentos de crisis del absolutismo, de los regímenes autoritarios o dictatoriales y de la dominación colonial salieron de nuevo los pueblos a las calles y plazas en la época moderna, reabrieron por momentos el espacio público de la soberanía popular, y desencadenaron las luchas que dieron lugar a los acontecimientos revolucionarios de la caída de los antiguos regímenes y a la fundación de las nuevas repúblicas democráticas.

En el antiguo régimen monárquico no existió un espacio público; la deliberación para la toma de decisiones "políticas" se recluyó en el recinto privado de los palacios, en el secreto de la corte, o quedó

${ }^{11}$ Cfr. É. de la Boétie, Discurso de la servidumbre voluntaria, Madrid, Trotta, 2008. 
simplemente in pectore, en la conciencia privada del Príncipe, a quien nadie podía pedir razones o justificación de sus decisiones soberanas. El Estado mismo llegó a ser entendido como propiedad privada de los príncipes. Los filósofos escolásticos confundieron incluso el léxico de lo político: la palabra latina civitas que empleaban para traducir la polis griega, se reinterpreta y se reemplaza por regnum, cuyo referente ya no es un colectivo, formado por los ciudadanos, sino un individuo, que es el príncipe, y su soberanía sobre un territorio. La fórmula griega zoon politikon se traduce, a su vez, como animal social, es decir, no se hace diferencia entre lo social y lo político. "Más que cualquier elaborada teoría, esta inconsciente sustitución de lo político por lo social revela hasta qué punto se había perdido el original concepto griego sobre la política"12. Los pensadores de las grandes Revoluciones modernas de los siglos XVIII y comienzos del XIX se inspiraron en las fuentes originarias del sentido, reactualizaron el significado auténtico del léxico de lo político, y "exploraron los archivos de la antigüedad para constituir su república, es decir, una forma de Estado en la que el dominio de la ley, apoyada en el poder del pueblo, debía poner fin a toda dominación del hombre sobre el hombre"13. Pero en los dos siglos posteriores, en el contexto de las nuevas desigualdades y la división de clases producida por el desarrollo de la economía capitalista, la igualdad de los ciudadanos quedó reducida a una declaración jurídica formal y el oscurecimiento, o el olvido, del sentido de lo político en el funcionamiento las instituciones estatales se ha ido profundizando. En el siglo XX las nuevas tecnologías de los instrumentos de control y dominación han hecho posible los totalitarismos que han suprimido los derechos, las libertades y la autonomía de la sociedad civil.

El Estado moderno ha ocupado de manera hegemónica el espacio público hasta producir la falacia de identificación de lo público con lo estatal, y el monopolio de lo político por parte una corporación o una clase política enquistada en las estructuras del poder administrativo. La crisis actual de legitimidad de ese modelo ha abierto una nueva oportunidad para la refundación de los espacios públicos autónomos,

${ }_{12}$ H. Arendt, La condición bumana, Barcelona, Paidós, 1993, p. 38.

${ }^{13}$ Cfr. H. Arendt, Macht und Gewsalt, München-Zürich, Pieper, 1970, pp. 41-42. 
abiertos y simétricos de los discursos políticos, para la democratización de las estructuras estatales, y para el empoderamiento de la ciudadanía, o de la sociedad civil.

Las prácticas políticas de "las democracias existentes" en el Estado moderno han sido contradictorias con el principio normativo de la elaboración de las decisiones colectivas a través de la discusión pública como condición de la legitimidad democrática. La teoría de la Realpolitik ha desacreditado como ineficiente el procedimiento de la deliberación pública y la búsqueda de consenso para la toma de decisiones, y lo considera incluso como inaplicable en el contexto competitivo de los juegos de poder. Se sostiene por lo tanto que los secretos de Estado, (no solamente en las relaciones internacionales, sino también en la política interna), son tan naturales y necesarios al gobierno como el secreto de los negocios y de las finanzas en los asuntos económicos ${ }^{14}$. No obstante el declarado propósito de marcar la diferencia de lo político con respecto a otras esferas de la actividad humana, estos puntos de vista del llamado "realismo político" identifican de nuevo lo político con la lógica de los juegos estratégicos de la lucha competitiva del mercado, cuyos procedimientos son compatibles con los de la estrategia militar, aunque los medios usados sean diferentes. El secreto de las deliberaciones, el factor sorpresa, el engaño del adversario, y otras estrategias de este tipo, pertenecen a las reglas constitutivas de los juegos mencionados, también de las campañas electorales y de las luchas de poder o por ocupar posiciones decisorias dentro del aparato del Estado, pero no son compatibles con los procedimientos democráticos legítimos de la toma de decisiones colectivas, ni con el proceso de la generación de poder en sentido propiamente político, en cuanto contrapuesto a la mera acumulación de fuerza, es decir, la acumulación de medios económicos (o de otro tipo) para obtener adhesión mediante las prácticas clientelistas o el miedo.

El problema no es meramente formal, o procedimental, porque lo que está en juego y se pierde en esta confusión es el sentido mismo de lo

${ }^{14}$ Cfr. C. Schmitt, Sobre el parlamentarismo, Madrid, Tecnos, 1996, p. 48. 
político. Si se comprende la política como un medio, o un instrumento para otra cosa que está más allá de lo político, entonces podrían llegar a legitimarse regímenes paternalistas, autoritarios o incluso dictatoriales, en la medida en que produzcan o realicen, de manera más o menos satisfactoria, los objetivos a los cuales debe servir ante todo la política, o los fines que le dan sentido y la legitiman. Más allá de la contradicción pragmática de esa suposición ${ }^{15}$, hay que decir que los mencionados regímenes son siempre políticamente inaceptables, simplemente por antidemocráticos $\mathrm{y}$, aunque realicen una aceptable administración y distribución de otros bienes, anulan o empobrecen el bien fundamental de la propia vida política, o de lo político mismo en cuanto tal.

Se trata de volver a pensar entonces si el proceso discursivo de la vida política, (o la democracia deliberativa), no tiene un sentido y un valor en sí mismo, porque solamente como ciudadanos autónomos de la polis desarrollan los hombres sus facultades de pensamiento y lenguaje, llegan a ser libres de toda dominación y se tratan como iguales ${ }^{16}$. Quisiera por lo menos preguntarme si no es posible pensar todavía de nuevo que la voluntad fundacional de la unión política, constitutiva de la polis, no es el interés, ni el miedo (como en Hobbes), sino la amistad civica, un sentimiento moral de reconocimiento recíproco entre los ciudadanos, el deseo de participación politica y de ejercer la ciudadanía, es decir, de ser parte del gobierno de la polis.

Se trata de pensar, con Aristóteles, que aun cuando tuvieran satisfechas todas sus necesidades, y especialmente entonces, los hombres

${ }^{15}$ En una dictadura, o en un régimen autoritario, no es posible corroborar si se satisfacen o no las condiciones de legitimación.

16 "Lo que distinguía la convivencia humana en la polis de otras formas de convivencia también humanas, que los griegos conocían muy bien, era la libertad. Pero esto no significa que lo político, o la política, se entendieran como un medio para posibilitar la libertad humana, una vida libre. Ser libre y vivir en una polis era en cierto sentido uno y lo mismo, puesto que, al formar parte de la polis, el hombre no podía estar sometido a la coacción de ningún otro como esclavo, ni a la indigencia de las necesidades vitales insatisfechas" ( $\mathrm{H}$. Arendt, ¿Qué es la política?, p. 69). 
buscarían unirse en una comunidad política como un bien o un fin en sí, de tal manera que el sentido de lo político no se tiene que explicar o justificar por alguna finalidad diferente y exterior a la propia vida política, sino que tiene su significado y valor en sí mismo. Es decir, la política es praxis, un tipo de acción no productiva, como la ética, y no poiesis, o techne. Es la forma de ser e interactuar propia y constitutiva de los hombres, en cuanto animales que tienen logos, que actúan juntos, que coordinan, acuerdan y complementan sus acciones y todos los demás intereses comunes mediante la palabra articulada como discurso racional comunicativo. Fuera de este espacio del discurso público, que es el espacio político, no hay libertad, porque el más débil cae inevitablemente bajo la dominación del más fuerte, rige la ley de la fuerza, y por lo tanto tampoco hay racionalidad. Los interlocutores de este discurso constituyente de la polis, o de la civitas, se denominan polites, o ciudadanos. Un ciudadano cualquiera es tan político como cualquier otro, porque ambos términos son sinónimos.

En el lenguaje común actual "lo político" ya no se entiende por cierto en este sentido, como definitorio del sentido del ser del hombre. Esta pérdida de sentido no se debe a la falta de comprensión, o la ignorancia del ciudadano común, sino a su conocimiento y experiencia de que en realidad la política no es sino un espacio de privilegios en el que ingresan solamente unos pocos, o una cierta clase social. "Ser-político" no es por cierto algo propio del común. "El político" no es un ciudadano cualquiera, sino un miembro de cierta clase, una corporación, una élite, o una profesión. No puede dejar de considerarse lo que hay de correcto en el punto de vista de M. Weber sobre la política como profesión en el Estado moderno, sin embargo esta profesión tiene sentido solamente con respecto a la administración de las funciones estatales, no con respecto a la constitución de lo político, ni a la construcción de poder. Pero ya hemos visto como en Max Weber no están claras las distinciones entre lo político y el Estado, ni entre el poder y la dominación (Macht und Herrschaft). El quehacer del político profesional en la administración pública no es praxis en el sentido aristotélico de la política y de la ética, sino poiesis, o techne, y tiene como fin la producción de ciertos bienes y servicios, o estados de cosas en la sociedad. En nuestro contexto argentino y latinoamericano la política no se deja asimilar sin embargo tampoco a la administración, sino que su 
autocomprensión se vincula de algún modo al concepto de lucha por el poder, o por la liberación.

En los comienzos de la época moderna hablaba Maquiavelo también de la política como un arte. Se puede mencionar incluso, como antecedente lejano de esta otra manera de ver, la vinculación entre la política y las artes de la retórica y la sofística que los griegos tenían en cuenta. Pero en Maquiavelo la política se asimila especialmente al arte de la estrategia, cuyo paradigma es la guerra. En nuestra comprensión no meramente estratégica, o no maquiavélica, la política no es la continuación de la guerra con otros medios, ni viceversa, tampoco la guerra es la continuación de la política con otros medios, sino que, por el contrario, las acciones bélicas comienzan cuando se ha cortado la conversación y no hay más diálogo, es decir, cuando la palabra, el discurso o la negociación, que son los procedimientos esenciales de la política, han fracasado o han sido desechados. El tipo de acción directa del guerrero y la estrategia militar no son parte del sentido constitutivo de lo político, sino un instrumento que los sujetos políticos, o los Estados pueden darse (o no) para la defensa de los ciudadanos y de la independencia de la polis. Pero la guerra en sentido propio tiene lugar fuera de los muros de la polis, frente a un enemigo externo; y cuando se enfrentan en su interior facciones enemigas en guerra, la política en cuanto tal queda suprimida: esa división es signo de que no hay ya una polis, o de que ésta se está destruyendo. Cuando la racionalidad comunicativa del discurso es reemplazada por la lógica de la relación amigo-enemigo se abandona el terreno de lo político y se ha ingresado, a veces sin saberlo, en otro juego, sin reglas, en el que todo vale. Este modelo conceptual de la guerra como definitorio de lo político, que proviene de Maquiavelo y de Hobbes, ha llegado a ser de nuevo hegemónico en la teoría política contemporánea, ya sea en la versión más económica de la política como lucha competitiva, o en la más antagonista de la relación amigo-enemigo que es el eje de la concepción del populismo de E. Laclau. Estas dos concepciones se creen opuestas, pero su lógica es la misma: la racionalidad estratégica.

En la misma tradición de la antigua Filosofía griega, como hemos visto, encontramos también, desde Platón, la tendencia a rebajar lo 
político a la categoría de un medio para la vida y para las actividades no políticas consideradas superiores, como la teoría, o la búsqueda de la verdad mediante la filosofía. La relación de subordinación, o de mediatización de lo político con respecto a otros bienes no políticos se mantiene formalmente inalterada en la historia posterior del mundo occidental, y este procedimiento es el que cobra la forma de la racionalidad estratégica. Lo que cambia sustantivamente son solamente los contenidos y los fines meta-políticos de la política, los ámbitos de la vida y los valores que pasan a ocupar el lugar central, o superior, y con respecto a los cuales se tiene que justificar ahora la política. En la Edad Media esta finalidad superior venía dada en la religión, y por eso el poder temporal estaba subordinado al poder religioso. Durante la modernidad, dice Arendt:

Lo religioso se sumergió en el ámbito de lo privado, mientras que el ámbito de la vida [en el sentido de la zoe], y de sus necesidades -que para los antiguos y medievales era lo privado por excelencia- recibió una nueva dignidad e irrumpió en lo público bajo la forma de lo social ly de lo económico] (...) el gobierno [o el Estado], en cuya área de acción se sitúa [o queda secuestrado] en adelante lo político, está para proteger la libre productividad de la sociedad y la seguridad de los individuos en su ámbito privado ${ }^{17}$.

Retomando el léxico de la Escuela de Frankfurt, podemos decir que la política ha caído desde la Edad Media, y especialmente en la Época

${ }_{17}$ H. Arendt, ¿Qué es la politica?, p. 80. En La volonté de savoir (Paris, 1976), Michel Foucault llama la atención sobre el hecho de que, desde el siglo XVIII, el eje de la política como gobierno del Estado ha llegado a ser la biopolítica y el biopoder. A partir de entonces sus investigaciones para los Cursos del Collège de France estuvicron centradas en esta cuestión, que es retomada actualmente por diversos autores. Así, siguiendo a Arendt y a Foucault, G. Agamben escribe que: "el ingreso de la zoe en la esfera de la polis, la politización de la nuda vida como tal, constituye el acontecimiento decisivo de la modernidad, que marca una transformación radical de las categorías político-filosóficas del pensamiento clásico" (G. Agamben, Homo Sacer. El poder soberano y la nuda vida, Valencia, Pretextos, 2003, p. 13). 
Moderna, bajo el régimen de la racionalidad instrumentall ${ }^{8}$. El concepto instrumental de la política ha venido retrocediendo en la historia occidental desde los fines metapolíticos más exigentes y elevados que le asignaban los antiguos y medievales (la libertad, el saber, el bien, la salvación), hasta los más modestos y elementales objetivos de impedir que los hombres se maten (Hobbes), o proveer para que puedan comer. Pero lo más desconcertante de la situación contemporánea es que este retroceso del realismo político hasta las condiciones de la nuda vida, aparece ahora como el menos creible, o como la más mentirosa de todas las promesas que han pretendido justificar el modelo del Estado moderno y las prerrogativas de la clase política.

Si tenemos en cuenta la experiencia de los totalitarismos y las grandes guerras del siglo XX, el inmenso desarrollo de los instrumentos de aniquilación física de la vida y de destrucción material por parte de los Estados más poderosos, la exclusión y la miseria que producen las políticas económicas, el hambre y las muertes en masa por las malas condiciones de salud en tantas regiones del globo, etc., tenemos que reconocer que la veta antipolítica del discurso de Arendt es simplemente la descripción de un dato de la realidad, y parece difícil de refutar su juicio cuando escribe que en el siglo pasado "lo político [o mejor: el Estado] ha llegado a convertirse precisamente en la mayor amenaza de aquello que, según la Edad Moderna, justifica su existencia, a saber, la amenaza de la mera posibilidad de vivir de la humanidad en su conjunto"19. Los datos de esta descripción no son el producto de algunas observaciones parciales y sesgadas, sino que, como advierte la autora: "Estas dos experiencias [os totalitarismos y el desarrollo de la carrera armamentista en la época de la Guerra Fría] son las experiencias políticas fundamentales de nuestra

\footnotetext{
18 No se trata de reactualizar la crítica radical de la racionalidad moderna y de la técnica al estilo de la primitiva teoría crítica de la sociedad, y de cierto heideggerianismo, sino de discutir la pretensión de universalidad de esta racionalidad, y más específicamente, el reduccionismo instrumental del sentido de lo político.

${ }^{19} \mathrm{H}$. Arendt, ¿Qué es la politica?, p. 63.
} 
época. Si alguno las pasa por alto, es como si no hubiera vivido en este mundo, que es el nuestro ${ }^{20}$.

Uno puede preguntarse a esta altura entonces por el significado de la propia reconstrucción conceptual de un sentido que parece carecer ya de todo referente empírico. Es posible que la idea de lo político que se esboza en este trabajo reconstructivo aparezca naturalmente como algo extraño, difícil de comprender, y alejado de la realidad política que conocemos o padecemos en nuestra experiencia. Este cuestionamiento es el que había llevado a $\mathrm{H}$. Arendt a reemplazar su pregunta inicial por el sentido de lo político, por esta otra, más radical y dramática: “¿tiene la política todavía algún sentido?”. En esta búsqueda de sentido que la atormentaba se le fue la vida, sin que pudiera terminar de escribir el prometido libro sobre la política que pensaba como su obra principal. Esta experiencia de vida de una mujer apasionada por la política, es instructiva sobre la dificultad del desafío de recuperar hoy honestamente el sentido de esta dimensión esencial de la existencia humana.

\section{Observaciones de Aristóteles sobre el significado de "República" y "Democracia"}

El tratamiento de la democracia en Aristóteles es complejo y un tanto fluctuante en los diversos libros de la Política. Este concepto no está claramente diferenciado del concepto general de la Politeia (República), como la constitución política de un pueblo de hombres libres e iguales. " $\mathrm{Si}$ como algunos opinan la libertad se encuentra principalmente en la democracia, y también la igualdad, esto se realizará de manera más perfecta cuando todos participan plenamente por igual. Y como el pueblo está en mayoría, y la decisión de la mayoría es soberana (kúrion), necesariamente será este régimen una democracia" (1291 b 35-39). La mayoría está formada casi siempre por los pobres, y "donde son los pobres los que gobiernan tenemos una democracia" (1279 b 3-4). Encontramos argumentos muy diversos sobre "la superioridad del 
gobierno de la mayoría sobre una minoría selecta (aristocracia)" (cfr. L III, 6).

Cuando Aristóteles diferencia las formas constitucionales (Libro III, cap. 5), al gobierno de uno sólo que tiene en vista el bien público lo denomina realeza, o monarquía, al gobierno de algunos pocos, aristocracia, y aclara que para el gobierno de muchos, o de la mayoría del pueblo, se puede usar el nombre común para todo gobierno constitucional, o para lo político en cuanto tal: politeia. La palabra "democracia" la reserva en este lugar para la desviación del gobierno constitucional que atiende solamente al interés de la mayoría, formada casi siempre por los pobres, sin tener en cuenta la utilidad común (1279 a 26-b 10 y 1293 a 38-40). La desviación que es más de temer para la utilidad común de la polis es "que los ricos se pongan de acuerdo con los pobres para atacar a la clase media" (1297 a 1), lo cual puede ocurrir por la influencia de los demagogos (1291 a 6-11).

Estas desviaciones de la democracia son menos probables si este gobierno se apoya en la clase media: "Es manifiesto que la comunidad política administrada por la clase media es la mejor, y que pueden gobernarse bien las ciudades en las cuales la clase media es numerosa y más fuerte, si es posible, que las otras dos clases juntas, o por lo menos que cada una de ellas [por separado], porque así sumándose a cualquiera de las otras inclina la balanza" (1295 b 35-39). "Y donde la clase media excede por su número a las otras dos clases extremas juntas, o por lo menos a una de ellas por separado, se hace posible que se consolide el gobierno constitucional" (1296 b 38-40). Es interesante destacar que este régimen de clase media es denominado por el autor, formalmente, democracia. "Las democracias son más seguras y de más larga duración que las oligarquías a causa de la clase media, cuyos miembros son más numerosos y participan más de los cargos políticos en las democracias que en las oligarquías" (1296 a 13-16). Pero como de hecho en la antigüedad no se daba prácticamente el caso de ciudades en la que la clase media fuera mayoritaria, este régimen intermedio "no ha sido considerado por los que tratan las formas constitucionales, y se limitan (como Platón) a enumerar las anteriores" (1293 a 41-43). No obstante esta observación de 
Aristóteles, "tampoco en su propia sistemática de la doctrina de la constitución la politeia ha sido considerada como era de esperar"21. El principio de la democracia, que el poder supremo es la voluntad de la mayoría, no especifica una determinada forma constitucional junto a otras, y si ese concepto no encuentra un nombre propio en algunos pasajes, es porque piensa un principio que es común a toda constitución política en cuanto diferente de la dominación despótica (cfr. 1294 a 14-15)22.

Hay que diferenciar todavía entre lo que nosotros llamaríamos hoy la constitución formal y la constitución real de una polis. Muchas veces encontramos que aunque la democracia no esté legalmente establecida en la constitución, "de hecho hay un gobierno democrático a causa del carácter del pueblo" teniendo en cuenta su decisión, el número y el posible acuerdo por ejemplo entre las clases populares. "De manera semejante, a la inversa, en otros pueblos la constitución puede ser legalmente democrática, pero inclinarse de hecho [por diferentes factores] hacia la oligarquía" (1292 b 12-16). En realidad las llamadas Repúblicas son siempre una mezcla de oligarquía (o aristocracia, en el mejor de los casos) y democracia (cfr. 1293 b 35-36). Por eso, las Repúblicas pueden ser llamadas "democracias" cuando en su constitución predomina el elemento popular, o también oligarquías, cuando el poder lo tienen los más ricos. De hecho en el mundo helénico, según observa nuestro autor, "la mayor parte de las constituciones son unas democráticas y otras

21 "Demokratie", en O. Brunne, W. Conze, R. Koselleck (Hrsg.), Geschichtliche Grundbegriffe: Historisches Lexikon zur politisch-sozialen Sprache in Deutschland, Sttutgart, Klett-Cotta Verlag, 1972-1997, Bd. 4, p. 832.

22 Como "democracia", las palabras "aristocracia", "oligarquía" y "dictadura" tienen en el lenguaje de Aristóteles unos matices semánticos que deberían estudiarse cuidadosamente. Aquí solamente quiero hacer algunas indicaciones. La elección de los ciudadanos que van a ocupar los cargos públicos o las magistraturas es, por ejemplo, un procedimiento típicamente aristocrático, porque con ello se intenta seleccionar a los mejores. El procedimiento más rigurosamente democrático sería la designación por sorteo entre todos los ciudadanos. No siempre se diferencian claramente aristocracia y oligarquía porque no existe la valoración negativa de los ricos y la exaltación del pobre, sesgos tan típicamente cristianos, exacerbados en la cultura hispano americana. 
oligárquicas", y esta fluctuación "se debe a que en ellas es a menudo exigua la clase media" (1296 a 2325).

El Filósofo ha esbozado también lo que puede considerarse como una secuencia genética de las formas constitucionales (L III, Cap. 10). "En un principio hubo gobiernos monárquicos". Hay una forma de monarquía que es como la extensión del gobierno doméstico de la casa a la ciudad, cuya población era escasa y cedía el gobierno a uno sólo, que se destacaba sobre todos los demás. "Pero cuando aconteció que hubo muchos semejantes en capacidad, no toleraron más el predominio de uno, sino que buscaron un gobierno en común y establecieron la república". La codicia de los ricos y el deseo de lucrar con los fondos públicos dio lugar más tarde a que el gobierno de la república cayera en manos de la oligarquía. Más tarde las rivalidades en el seno de esta clase dominante derivaron en la tiranía de uno sólo, o de un número muy reducido y debilitado por sus luchas internas. Finalmente la multitud impuso el poder del número sobre los tiranos y dio origen a la democracia, "y como las ciudades se han hecho cada vez mayores, no es fácil que pueda surgir otra forma de gobierno distinta de la democracia" (1286 b 8-21). Entre los bárbaros y en las naciones asiáticas han perdurado formas despóticas de poder monárquico, quizás porque "como los bárbaros son de carácter más servil que los griegos, y los asiáticos más que los europeos, soportan sin mayores quejas la dominación despótica" (1285 a 19-20).

Recibido: 07/2013. Aprobado: 10/2013 